\title{
HALAQAH DAN MUNAZHARAH WARISAN PENDIDIKAN ISLAM KLASIK
}

Oleh:

\author{
Asmar Yamin Dalimunthe ${ }^{1}$
}

\begin{abstract}
Abstarct
The classical period is a symbol of the progress of the glorious Islamic ummah throughout history. The duration of that glory has not matched it, including the glory of America. Halaqah as a circular learning system is one of the legacies of classical Islamic education that is still used today. Munazharah is a stage of debate to measure abilities as well as the heritage of classical Islamic education that is in demand. Munazharah in the Islamic education system is hardly unseen to be used by Muslims. But this munazharah system is still enshrined in various competitions, such as in MTQ.
\end{abstract}

Keyword: Halaqah, Munaqarah, Education, Clasic

\section{PENDAHULUAN}

Klasik bukanlah berarti simbol kekunoan, tetapi simbol dari keindahan. Pada zaman klasik dalam Islam tahun 650-1250 M disebut dengan zaman keemasan. Zaman ini menunjukkan prestasi gemilang umat Islam. Menurut kesaksian al-Fasi bahwa sampai abad ke-18, Halaqah masih tetapi dipertahankan sebagai metode utama proses belajar mengajar di Mesjid al-Haram. ${ }^{2}$ Banyak ulama besar tentunya yang lahir dari halaqah-halaqah, termasuk Halaqah Mesjid Haramain. Di antara mereka Ibrahim alKurani adalah alumni Halaqah Mesjid Nabawi, murid dari al-Qusairi. Kemudian ia mengajar di "almamaternya" mengajar hadis, fiqh, tafsir, dan tasauf. Ia dapat menarik murid dari seluruh penjuru dunia Muslim untuk menghadiri Halaqahnya. ${ }^{3}$ Selain itu, Isa al-Magribi juga alumni Halaqah Mesjid Nabawi.Ia mengajar juga di "almamaternya" dan mengajar di Mesjid al-Haram. Beliau adalah ilmuan yang mumpuni yang tidak dapat diremehkan. ${ }^{4}$

Metode munazarah dan juga disebut jadal, belakangan disebut bahs adalah arena intelektual untuk menyeleksi ilmuan-ilmuan nomor wahid (pertama). Dari metode ini banyak diketahui pakar-pakar ilmu keislaman, termasuk al-Gazali setelah kematian gurunya al-Juwaini sering mengikuti kegiatan menazarah sampai ia mencapai puncak karir akademisnya sebagai "guru besar". Dari tradisi munazarah yang berkembang dari

\footnotetext{
${ }^{1}$ Penulis Adalah Dosen PGMI STAIRA Batang Kuis Deli Serdang, Gmail: asmaryamindlt@gmail.com

${ }^{2}$ Azyumardi Azra, Jaringan Ulama TImur Tengah dan Kepulauan Nusantara Abad XVII\&XVIII: Edisi Perenial (Jakarta: Kencana, 2013), h. 83.

${ }^{3}$ Azra, Jaringan ..., h.101.

${ }^{4}$ Azra, Jaringan....,h. 107.
} 
Bagdad ini dan berkembang ke seluruh penjuru dunia Islam, dapat diketahui para pakar yang kemudian dikenal dengan sebutan "ra'is"

Sistem Halaqah sampai sekarang mungkin sampai yang akan datang masih banyak digunakan dalam belajar. Semenetara munazharah dalam konteks menguji orang terbaik pun gemar dilakukan sistem modern, walaupun tidak lagi dalam konteks keilmuan Islam mainstream.

Tulisan ini, secara khusus akan menyoroti metode halaqah dari sisi filosofis dan historis. Sisi filosofis untuk memahami makna dasar dari halaqah, sementara sisi historis (sejarah) untuk melihat praktek halaqah. Demikian juga munazharah akan dilihat dari sisi filosofis dan historis

\section{KONSEP DAN PEMBAHASAN}

\section{Metode Halaqah}

Kamus Munjid menyebut "setiap yang bundar itu disebut dengan halaqah". Hasan Asari mengutip dari Nakosteen halaqah berarti lingkaran. ${ }^{6}$ vBelajar dengan sistem melingkar di Indonesia masih sering ditemukan dalam ruang kelas TK dan juga ruang belajar Pascasarjan. Sistem ini sering juga ditemukan di ruang rapat. Ada kejadian penting yang menggunakan sistem ini, yaitu Konferensi Meja Bundar. Itu semua menggunakan sistem halaqah yang melingkar.

Halaqah sebelum diadakan di Mesjid-Mesjid pada mulanya juga diadakan di rumah-rumah seperti pendidikan Kuttab. Stanton menulis bahwa Ibn Sina memiliki Halaqah di rumahnya. Pembelajaran berlangsung sejak fajar sampai pertengahan waktu pagi. ${ }^{7}$ Sistem pembelajarannya membaca dan berdiskusi. Al-Gazali jug dikenal pernah memiliki kelompok belajar Halaqah di rumahnya, sedangkan murid-muridnya para ilmuan. Reputasi dan populeritas seorang syeikh Halaqah turun menentukan sedikit banyaknya murid. ${ }^{8}$

Walaupun Halaqah ada di rumah-rumah, tetapi pada umumnya diadakan di Mesjid-Mesjid.Mesjid adalah lembaga pendidikan Islam sebelum Madrasah. ${ }^{9}$ Tipe Mesjid ada yang berbentuk Jami' dan ada yang non Jami'. Sebagaimana ditulis Stanton bahwa berdasarkan hadis Nabi Muhammad Saw, hanya satu Mesjid Jami' yang boleh didirikan di setiap kota. Penambahan Mesjid Jami' dalam satu kota harus diputuskan berdasarkan fatwa atau keputusan hukum. ${ }^{10}$ Pendidikan Mesjid baik Jami' maupun non

${ }^{5}$ Fr. Louis Ma'luf al-Yassu'i dan Fr. Bernard Tottel al-Yassu'i, Munjid, cet. 28 (Beirut: Dar ElMachreq Sarl Publisher, 1986), h. 150.

${ }^{6}$ Hasan Asari, Menyingkap Zaman Keemasan Islam: Kajian atas Lembaga-Lembaga Pendidikan (Bandung: Mizan, 1994), h. 37.

${ }^{7}$ Menurut kesaksian an-Nakhli bahwa sampai abad ke-18, di Mesjid al-Haram.Halaqah biasanya dilaksanakan pada pagi hari, setelah shalat Subuh, 'Ashar, Maghrib, dan Isya. Baca Azyumardi Azra, Jaringan Ulama TImur Tengah dan Kepulauan Nusantara Abad XVII\&XVIII: Edisi Perenial, h. 115. Pada siang hari proses belajar mengajar pindah ke Madrasah sekitar Masjid. Baca Ibid., h. 83.

${ }^{8}$ Charles Michael Stanton, Pendidikan Tinggi Dalam Islam: Sejarah dan Peranannya Dalam Kemajuan Ilmu Pengetahuan, terj. Afandi dan Hasan Asari (Jakarta: Logos, 1994), h. 156.

${ }^{9}$ Pendidikan Islam sejak di Mesjid dilaksanakan dalam Halaqah, Majlis Tadris, dan rumah guru.

Baca Azyumardi Azra, Jaringan Ulama TImur Tengah dan Kepulauan Nusantara Abad XVII\&XVIII: Edisi Perenial, h. 57.

${ }^{10}$ Charles Michael Stanton, Pendidikan Tinggi Dalam Islam: Sejarah dan Peranannya Dalam Kemajuan Ilmu Pengetahuan, h. 35. 
Jami' menggunakan sistem halaqah. ${ }^{11}$ Mesjid Jami' biasanya dibangun oleh Negara di bawah pengawasan khalifah atau gubernur. Sementara Mesjid non Jami' didirikan oleh kelompok tertentu dengan dukungan dana dari masyarakat. Kemudian Mesjid Jami' selain berfungsi sebagai tempat ibadah dan tempat belajar Halaqah, juga dijadikan media penyambung antara pemerintah dan rakyat. ${ }^{12}$ Fungsi mesjid untuk mengumumkan hal-hal yang penting bagi masyarakat masih banyak kita temukan sampai sekarang ini. Ada orang meninggal diumumkan di Mesjid-Mesjid. Ada kegiatan immunisasi diumumkan di Mesjid-Mesjid, musyawarah masyarakat juga sering dilakukan di Mesjid-Mesjid, dan lain-lain. Sementara Mesjid non Jami' lebih banyak digunakan untuk tempat ibadah dan ada juga yang digunakan untuk Halaqah.

Sistem pendidikan Halaqah di mana sang Syeikh atau guru biasanya duduk di dekat dinding atau tiang Mesjid, sementara peserta didiknya duduk di depannya, membentuk setengah lingkaran. ${ }^{13}$ Adalah merupakan kebiasaan dalam sistem Halaqah bahwa peserta didik yang lebih tinggi pengetahuannya duduk di posisi terdepan dengan syaikh, sementara posisi yang paling rendah pengetahuannya berada pada posisi yang lebih jauh dari syeikh. ${ }^{14}$ Dengan demikian, jauh-dekatnya posisi duduk seorang peserta didik Halaqah ditentukan oleh tingkat pengetahuannya. Dalam hal posisi terdekat dari syeikh, terdapat juga dalam sistem shalat jama'ah, dimana orang yang berpengetahuan dan bisa menggantikan imam lah yang berhak berada diposisi belakang terdekat imam. Jika suatu saat, imam tidak bisa melanjutkan imamah karena faktor syar'i, maka makmum yang di belakangnya yang akan menggantikannya. Selain itu, makmum yang di belakang imam itu berfungsi mengingatkan imam jika imam salah atau lupa baik dalam bacaan maupun dalam tertib shalat.

Sistem belajar Halaqah, ${ }^{15}$ syaikh membuka perkuliahan atau pembelajaran dengan do'a singkat. Selanjutnya, syaikh menjelaskan secara umum tentang topik yang akan dibahas sambil menghubungkannya dengan pembahasan yang telah lalu. Syaikh biasanya menyampaikan materi dengan metode Imla' atau dikte. Setelah itu, sang syeikh menjelaskan yang didiktekan. Bahasa dan tingkat penjelasan disesuaikan dengan pengetahuan peserta Halaqah secara umum. Menjelang akhir pembelajaran atau perkuliahan, dilakukan proses tanya-jawab. ${ }^{16}$

Ada kalanya waktu itu juga digunakan syaikh untuk memeriksa, mengoreksi, dan menambah catatan peserta Halaqah berdasarkan keperluan. ${ }^{17}$ Karena jumlah peserta

\footnotetext{
${ }^{11}$ Hasan Asari, Menyingkap Zaman Keemasan Islam: Kajian atas Lembaga-Lembaga Pendidikan, h. 37. Jami' juga digunakan untuk menunjukkan sebuah lembaga pendidikan. Baca George Makdisi, The Rise of Colleges (Edinburgh: Edinburg University Press, 1981), h. 12.

${ }^{12}$ Charles Michael Stanton, Pendidikan Tinggi Dalam Islam: Sejarah dan Peranannya Dalam Kemajuan Ilmu Pengetahuan, h. 35.

${ }^{13}$ Hasan Asari, Menyingkap Zaman Keemasan Islam: Kajian atas Lembaga-Lembaga Pendidikan, h. 37.

${ }^{14}$ Ibid.

${ }^{15}$ Belajar Halaqah biasanya dilakukan di pagi hari. Charles Michael Stanton, Pendidikan Tinggi Dalam Islam: Sejarah dan Peranannya Dalam Kemajuan Ilmu Pengetahuan, h. 36.

${ }^{16}$ Hasan Asari, Menyingkap Zaman Keemasan Islam: Kajian atas Lembaga-Lembaga Pendidikan, h. 37.

${ }^{17}$ Ibid., h. 38.
} 
Halaqah mulai dari 10-20 orang, ${ }^{18}$ maka pada akhir pembelajaran syaikh mengetahui kekurangan masing-masing peserta. Dalam pendidikan Halaqah, syaikh juga menganjurkan peserta untuk membaca materi tambahan dan terbuka untuk berbeda pendapat dengan syeikh. ${ }^{19}$

Tentang tanya-jawab dan debat akademik peserta dan syeikh Halaqah lebih lanjut disebutkan oleh Nakosteen yang dikutip oleh Hasan Asari:

Mahasiswa yang sudah lebih maju, bahkan pemula, dan pengunjung (bukan mahasiswa tetap), didorong untuk bertanya kepada syaikh tenang apa saja dan bebas untuk tidak sependapat dengan pandangan syaikhnya, bahkan untuk menentang dan membenarkan pernyataan-pernyataannya. Tidak mengherankan kalau debat antara mahasiswa dan syaikh adalah hal yang sering terjadi dan kerap kali menghasilkan argument-argumen yang hangat dan keras. Tetapi semua ini dilakukan atas nama penyelidikan dan kegiatan ilmiah. ${ }^{20}$

Dalam hal kebolehan berbeda pendapat, terkesan pendidikan Halaqah menumbuhkembangkan pendidikan yang demokratis, di mana peserta didik dibolehkan berbeda pendapat dengan syeikhnya. Sistem keterbukaan ini masih dirasakan relevan dalam konteks pendidikan modern. Selain itu, dorongan untuk bertanya tidak selamanya didasari oleh ketidaktahuan karena dalam pepatah Arab disebutkan bahwa, "husnu assuali nisfu al'ilm: pertanyaan yang baik menunjukkan setengah dari ilmunya". Artinya, pandai bertanya adalah orang yang berpengetahuan. Selain itu, tanya-jawab ini dapat mengoreksi dan sekaligus memperdalam pengetahuan peserta Halaqah dari apa yang disampaikan oleh syeikh. Selain itu, tahapan tanya-jawab menunjukkan kesiapan syaikh dalam mengajar. Secara psikologis, orang yang tidak siap untuk ditanya persiapannya tidak begitu mapan. Adakalanya dosen tidak menyukai pertanyaan yang tidak bisa ia jawab. Padahal secara filosofis, jika dosen tidak mengetahui jawaban suatu pertanyaan, maka ia berkesempatan mencari tahu jawabannya, sehingga ia memperoleh pengetahuan yang baru. Sistem Halaqah nampaknya menghormati pertanyaan-pertanyaan yang bermutu, walaupun bisa saja sang syeikh tidak selamanya dapat menjawabnya.

Jika Halaqah terlalu besar, sehingga suara syaikh kurang kedengaran, maka $m$ ' $^{2} \mathrm{~d}^{21}$ akan mengulangi ucapan-ucapan syeikh agar kedengaran ke semua peserta khususnya mereka yang duduk jauh dari posisi syeikh. ${ }^{22}$

Ada dua jenis Halaqah yang dikenal dalam sistem pendidikan Islam klasik, yaitu yang mengkaji ilmu-ilmu agama secara umum dan yang mengkaji fiqh secara khusus. Halaqah Mesjid Jami', dipimpin oleh seorang syeikh yang diangkat oleh khalifah. Dalam pengangkatan syeikh di Halaqah Mesjid Jami', pemuka masyarakat dan juga

\footnotetext{
${ }^{18}$ Tentang jumlah peserta belajar Halaqah, Ahmad Salabi menyebut tidak terbatas.Halaqah Mesjid pada umumnya pesertanya lebih banyak daripada jumlah murid yang belajar di dalam satu kelas pada Madrasah.Rida al-Din al-Naisaburi, peserta Halaqahnya berjumlah 400 ahli fiqh.Abi at-Tayyib asSa'luki, mufti Naisabur, peserta Halaqahnya lebih dari 500 orang. Abu Hamid al-Isfaraini, yang mengajar di Halaqah Mesjid al-Mubarak di Bagdad, jumlah pesertanya antara 300-700 orang. Baca Ahmad Salabi, Tarikh at-Tarbiyah al-Islamiyah (Beirut: Dar al-Kasysyaf, 1945), h. 293.

19 Hasan Asari, Menyingkap Zaman Keemasan Islam: Kajian atas Lembaga-Lembaga Pendidikan, h. 37.

${ }^{20}$ Ibid.

${ }^{21}$ Dalam bahasa mu'id berarti yang mengulangi.Dalam sistem Halaqah mu'id itu adalah seorang mahasiswa paling senior dari seorang syeik. Tugasnya mengulangi kembali perjelasan syeikh pada waktu perkuliahan, agar dapat dipahami oleh semua peserta. Baca Ibid., h. 39.

${ }^{22}$ Charles Michael Stanton, Pendidikan Tinggi Dalam Islam: Sejarah dan Peranannya Dalam Kemajuan Ilmu Pengetahuan, h. 37. 
para bangsawan berusaha mempengaruhi khalifah. Di kota-kota provinsi, syaikh diangkat oleh para gubernur. ${ }^{23}$ Artinya pengangkatan syeikh Halaqah Mesjid Jami' bersifat desentralistik. Khatib al-Bagdadi contohnya ketika ditunjuk oleh Khalifah alQaim menjadi syaikh di Mesjid Jami' al-Mansur dengan terlebih dahulu khalifah mendatangi ketua Perserikatan Syikh, Naqib al-Hasyimiyin.Naqib al-Hasyimiyin memberi izin kepada al-Bagdadi untuk mengajar hadis di Mesjid Jami' tersebut.Kasus itu menunjukkan bahwa seorang khalifah memiliki otoritas untuk menunjuk seorang syeikh. ${ }^{24}$ Dengan sendirinya dapat diduga bahwa syeikh Halaqah di Mesjid non Jami' tidaklah ditentukan oleh khalifah dan tidak juga oleh gubernur, tetapi ditentukan oleh kelompok masyarakat yang mendirikannya atau ditentukan oleh pewaqifnya.

Seorang syeikh Halaqah hanya boleh memimpin satu Halaqah dalam satu Mesjid. Ia bisa menjadi syeikh Halaqah di Mesjid yang lainnya. Dengan sistem ini, seorang syeikh dapat menambah tugas mengajarnya, sehingga tambah muridnya dan sekaligus bertambah penghasilannya. ${ }^{25}$ Syeikh Halaqah Mesjid biasanya diangkat untuk masa jabatan seumur hidup kecuali ada alasan lain, karena syeikh melanggar ajaran agama dan moralitas. Dengan pelanggaran ajaran agama dan atau moralitas, maka syeikh dapat dipecat oleh yang memberi mandat kepadanya. ${ }^{26}$

Bisa saja karena faktor duniawi, di mana syeikh mendapat pengsilan dari jabatannya, sehingga sering terjadi praktek nepotisme, di mana syeikh sering terjadi, berusaha mewariskan jabatannya kepada anak-cucunya atau murid kesayangannya. ${ }^{27}$

Nama Halaqah adakalnya berdasarkan nama Mesjidnya. Terkadang berdasarkan nama syeikhnya dan ada juga berdasarkan disiplin ilmu yang diajarkannya. ${ }^{28}$

Kajian agama yang umum di Halaqah mencakup tafsir, hadis, usul fiqh, nahwu, sarf, dan sastra Arab. Sementara ada juga kajian khusus fiqh. Selain ilmu agama sebagaimana disebutkan, maka tidak diajarkan oleh syeikh di Halaqah Mesjid. ${ }^{29}$ Dengan demikian, Halaqah bisa disebut kelompok belajar ilmu-ilmu agama.

Murid-murid Halaqah Mesjid Jami' tidak dipungut biaya. Mereka bebas datang dan sekaligu bebas keluar. Selain itu, bagi murid Halaqah tidak ada batasan usia. ${ }^{30}$ Ini menyerupai jama'ah khutbah Jum'at. Hanya saja kata Stanton, bagi mereka yang masih muda-muda dipersiapkan dalam bahasa Arab, sastra, dan pengetahuan dasar Alquran dan Sunnah. ${ }^{31}$ Dalam sistem Halaqah ada yang bukan syeikh dan bukan juga murid atau peserta, tetapi mereka yang membantu tugas syeikh dalam mengajar. Profesi itu bernama naib, mu'id, dan mufid. Naib secara bahasa adalah wakil. Ia bertugas menggantikan syeikh atau mudarris (sebutan syeikh yang mengajar fiqh) jika berhalangan atau atas permintaan syaikh atau mudarris. Sementara murid senior yang bertugas mengulangi penjelasan syeikh atau mudarris agar dapat dipahami oleh semua

\footnotetext{
${ }^{23}$ Ibid., h. 35 .

${ }^{24}$ George Makdisi, The Rise of Colleges, h. 15.

${ }^{25}$ Charles Michael Stanton, Pendidikan Tinggi Dalam Islam: Sejarah dan Peranannya Dalam Kemajuan Ilmu Pengetahuan, h. 36.

${ }^{26}$ Ibid.

${ }^{27}$ Ibid.

${ }^{28}$ Ibid

${ }^{29}$ Ibid

${ }^{30}$ Ibid., h. 37.

${ }^{31}$ Ibid.
} 
murid. Bagi murid kelas rendah atau pemula, maka dibantu oleh seorang mufid. ${ }^{32}$ Mufid secara bahasa bisa diartikan yang memberi manfaat.

Profesi syaikh atau guru secara umum sepanjang sejarah Islam klasik yang didukung oleh lembaga-lembaga wakaf tidak dapat menjadi hartawan, tetapi dapat dikatakan berpenghasilan menengah. Di antara penyebabnya dilema menerima imbalan dari murid masih terjadi sepanjang sejarah Islam klasik. Sementara syeikh atau guru yang terkenal ada juga yang kaya walaupun sedikit, tetapi sangat sedikit bukti ada orang memilih profesi syaikh atau guru karena motif ekonomi. ${ }^{33}$

Halaqah atau lingkaran belajar sebetulnya tidak saja diadakan di rumah dan di Mesjid ada juga yang diadakan di rumah sakit dan laboratorium. Hanya saja materi yang diajarkan tidaklah ilmu-ilmu agama, tetapi ilmu-ilmu alam. Sedangkan metodenya tetap dengan mengedepankan rasionalitas dan kritisisme. Karya-karya filsafat juga tidak diajarkan di Halaqah yang bersifat formal, maka meteri ini diajarkan secara informal di rumah-rumah. Kalau tidak ada Halaqah filsafat, tidak mungkin karya-karya al-Kindi, Ibn Sina, al-Farabi, dan Ibn Rusyd tersebar luas ke seluruh penjuru wilayah kekuasan Islam kata Stanton. ${ }^{34}$

Halaqah selain diselenggarakan di rumah, Mesjid, Rumah Sakit, dan Laboratorium, juga ada yang diselenggarakan di istana-istana. Pada masa kekhalifaan Harun ar-Rasyid dan al-Ma'mun, Halaqah ini sangat terkenal karena ketinggian kualitas diskusinya dan itu diadakan di istana. Bahkan, Khalifah al-Ma'mun sering menjadi moderator diskusinya. ${ }^{35}$

Perlu juga menjadi catatan bahwa pendidikan Halaqah bukanlah pendidikan dasar seperti di Kuttab. Setidaknya pendidikan Halaqah sebagai lembaga pendidikan dan sebagai metode belajar berlaku untuk pendidikan menengah, dan tinggi. ${ }^{36}$

Jika dianalisis lebih dalam halaqah pada mulanya disebut karena sistem kelompok belajar yang mengadakan pendidikan dan pengajaran secara melingkar. Sistem belajar yang melingkar di dalam ruangan belajar seperti sekarang ini, jarang ditemukan pada tingkat pendidikan dasar dan menengah. Pada umumnya belajar dengan sistem klasikal sekarang ini, khususnya pada jenjang pendidikan dasar dan menengah, menggunakan bentuk sejajar berbaris. Artinya, pendidikan dengan peserta didiknya berhadapan. Tetapi di pascasarjana, sistem belajar halaqah ini banyak ditemukan.

Dilihat dari tempat-tempat belajar yang disebut dengan halaqah, maka ia bagaikan kata lain dari lembaga pendidikan atau sekolah. Sekolah itu bisa di rumah, bisa di Mesjid, dan bisa juga di tempat lain. Sampai di sini pun halaqah masih cenderung disebut sebagai sistem pendidikan daripada metode.

Ketika kegiatan belajar-mengajar berlangsung, seorang syeikh atau guru duduk di dekat dinding, sementara murid-muridnya duduk di depannya. Aturan duduk pun ditentukan dengan kemampuan murid. Semakin bagus penguasaannya terhadap materi pelajaran, maka semakin dekat posisinya dengan guru. Hal ini pun masih cenderung halaqah sebagai sistem.

\footnotetext{
${ }^{32}$ Ibid., h. 40-41. baca juga Hasan Asari, Menyingkap Zaman Keemasan Islam: Kajian atas Lembaga-Lembaga Pendidikan, h. 39-41.

${ }^{33}$ Charles Michael Stanton, Pendidikan Tinggi Dalam Islam: Sejarah dan Peranannya Dalam Kemajuan Ilmu Pengetahuan, h. 39.

${ }^{34}$ Ibid, h. 159.

${ }^{35}$ Ibid. h. 161.

${ }^{36}$ Ahmad Syalabi, Sejarah Pendidikan Islam, terj.Muchtar Jahya dan M. Sanusi Latief (Jakarta: Bulan Bintang, 1973), h, 336.

Halaqah dan Munazharah.... 
Dalam kegiatan inti belajar-mengajar, syeikh membuka perkuliahan dengan dimulai dengan do'a singkat. Kemudian membahas topik yang akan dibahas, sambil menguhungkannya dengan pelajaran yang lalu. Syeikh biasa memberikan materi dengan dikte. Lalu syeikh menjelaskan yang didiktekan. Di akhir kegiatan belajar-mengajar diadakan tanya-jawab. Pada saat tanya-jawab itu, ada kalanya syeikh memeriksa catatan-catatan peserta halaqah, sehingga syeikh bisa membenarkan kesalahan. Pada tahap inti ini, halaqah lebih cenderung sebagai metode pengajaran.Namun secara umum, halaqah itu cenderung sebagai sistem. Dalam sistem itu ada metode pengajaran.

\section{Metode Munazarah}

Dalam Mu'jam Mustalahat al-'Ulum al-Tarbawiyah kata “munazarah" berarti "debate". ${ }^{37}$ Kata lain yang sama maknanya dengan munazarah adalah jadal. ${ }^{38}$ Belakangan kedua istilah itu menghilang dalam perjalanan sejarah dan digantikan dengan kata "bahs" yang subsatansinya sama. ${ }^{39}$ Karena kegiatan ini munazarah tanyajawab dan dialog, maka secara teoritis dengan mudah ditemukan di dalam Alqur'an. ${ }^{40}$ Begitu pun beberapa ilmuan Barat ada yang berpendapat bahwa munazarah ini hasil adopsi dari disputatio Yunani. ${ }^{41}$ Terlepas dari asal-muasal dari munazarah ini, yang jelas hal ini menjadi fenomena dalam sejarah intelektual Islam.

Sejak masa Rasulullah sampai masa empat Khulafa ar-Rasyidun, jarang mereka membutuhkan bantuan dalam menetapkan hukum yang terjadi pada masyarakat. Selain mereka itu shaleh juga dalam ilmunya. Pasca masa Khulafa ar-Rasyidun, ulama-ulama banyak membutuhkan orang lain karena ilmu mereka tidak sebagaik para pendahulunya. Kemudian mereka justru ada yang bekerja untuk tujuan non agama. Pada masa khulafa ar-Rasyidun, Negara minta pendapat mereka dalam menetapkan suatu hukum, tetapi setelah mereka, malah ulama-ulama itu yang banyak meminta posisi pada Negara. Pada saat inilah berkembang pesat ilmu munazarah. ${ }^{42}$

Munazarah sebagai metode skolastik yang mengedepankan rasionalitas dan kritisisme menurut George Makdisi, berfungsi untuk mempersiapkan mahasiswa hukum dapat memberi fatwa. ${ }^{43}$ Ahli hukum yang berprofesi sebagai pengacara, jaksa, dan juga hakim membutuhkan kemampuan berdebat yang berkualitas.

Kualitas hasil pemikiran mereka akan dapat dinilai oleh public. Dalam konteks peradilan di Indonesia, hakim berhak memutuskan apa saja, termasuk untuk tidak mengikuti pikiran dan hati nuraninya karena motif negative, tetapi keputusannya akan "dicemoohkan" baik pengacara maupun jaksa. Ketika keputusan hakim itu dirasa tidak benar dan berkeadilan oleh jaksa maupun pengacara, maka mereka dapat menempu jalur hukum banding. Secara administrative juga keputusan hakim dapat dinilai oleh Komisi Yudisial. Secara sosoilogis juga publik, baik yang memiliki pengetahuan tentang hukum atau tidak terbuka untuk menilai keputusan hakim. Tuntutan jaksa di pengadilan dan

${ }^{37}$ Syauqi as-Sayyid as-Syarifi, Mu'jam Mustalahat al- 'Ulum al-Tarbawiyah (Riyad: Maktab alAbikan, 2000), h. 126

${ }^{38}$ Hasan Asari, Menguak Sejarah Mencari 'Ibrah (Bandung: Cita Pustaka, 2006), h. 181.

${ }^{39}$ Ibid., h. 185.

${ }^{40}$ Ibid., h. 183 .

${ }^{41}$ Ibid., h. 182.

${ }^{42}$ Hasan Asari, Nukilan Pemikiran Islam Klasik (Yogyakarta: Tiara Wacana Yogya, 1999), h. 96.

${ }^{43}$ George Makdisi, The Rise of Colleges, h. 128. 
pembelaan pengacara terhadap kliennya juga dapat dinilai dari berbagai pihak, apalagi media elektronik dan social di zaman teknologi dan informasi ini berkembang pesat.

Panggung terbuka untuk menilai teori dan praktek hukum di Indonesia secara intensif juga dilakukan oleh program TV seperti Indonesia Lawyer Club di TV One. Untuk itu, ilmu metode munazarah ril dibutuhkan dan dipraktekkan. Hanya saja praktek ilmu metode munazarah seperti yang disinyalir oleh al-Gazali lebih banyak bertujuan ingin mencari kemenangan bukan semata-mata untuk mencari kebenaran. Tujuan yang seperti ini dikatakan oleh al-Gazali tercela. ${ }^{44}$

Ilmu metode munazarah ini menurut Makdisi mutlak dibutuhkan oleh mufti. ${ }^{45}$ Ada lembaga yang resmi di suatu Negara untuk mengeluarkan fatwa baik karena diminta atau tidak mereka mengeluarkan fatwa. Dalam proses mengeluarkan fatwa, tentu ada pembahasan yang menggunakan metode perdebatan ilmiah dari anggota majlis fatwa. Di Indonesia lembaga ini seperti MUI, Majlis Tarjih di Muhammadiyah, dan Bahsu al-Masail di Nahdatul Ulama. Lembaga-lembaga ini diduga memang cenderung tidak menggunakan ilmu metode munazarah untuk mencari kemenangan, tetapi untuk mencarai kebenaran.

Sebagaimana dikutip oleh Hasan Asari dari al-Gazali bahwa metode munazarah untuk menentukan ketetapan hukum itu dibolehkan, tetapi metode ini tidak tepat untuk diperaktekkan dalam Ilmu Kalam. Dalam sejarah Islam, peraktek metode munazarah dalam Ilmu Kalam telah menimbulkan pertumpahan darah dan kekacauan negeri. ${ }^{46}$

Pada masa Bani Abbas, Masjid-Masjid yang didirikan oleh pengusaha pada umumnya melengkapi fasilitas pendidikan, termasuk fasilitas untuk munazarah berbagai ilmu pengetahuan. ${ }^{47}$ Munazarah berbagai ilmu pengetahuan jika untuk mencari kebenaran, maka itu menjadi baik. Sementara jika mental berdebatnya hanya mencari kemenangan dan apalagi untuk membela pendapat kelompok tertentu, maka itu bisa menjadi kontra produktif. Lihatlah saat perilaku politikus dalam berdebat, jarang sekali terkesan mereka untuk mencari kebenaran. Kesan ingin mencari kemenangan pendapat kelompoknya lebih mudah ditangkap daripada ingin mencari kebenaran. Jargon politik, "right or wrong is my party: benar atau salah adalah partai saya" dengan mudah dipahami bahwa mereka berdebat bukan untuk mencari kebenaran, tetapi mencari kemenangan. Untuk itu, debat maupun dialog yang sering kita saksikan di media televise jika merujuk pada pendapat al-Gazali, maka tidak perlu.

Agar metode munazarah berguna, al-Gazali sebagaimana dikutip oleh Hasan Asari, memberi syarat-syarat sebagaimana berikut:

1. Sebagai sebuah metode pencarian kebenaran, munazarah dianggap fard kifayah. Karenanya, orang yang melakukannya haruslah terlebih dahulu memenuhi seluruh fard 'ainnya;

2. Ia harus pula telah melaksanakan fard kifayah-nya yang lebih penting;

3. Seorang yang ber-munazarah mestilah seorang mujtahid yang telah mampu membentuk pandangannya sendiri dan tak lagi tergantung pada pendapatpendapat imam yang lain;

4. Topik yang didiskusikan dalam munazarah harus actual dan riil;

5. Munazaah dilaksanakan secara tertutup, tanpa harus dihadiri khalayak ramai;

\footnotetext{
${ }^{44}$ Gazhali, Ihya Ulum ad-Din (Semarang: Toha Putra, t.t.), Jilid I, h. 45.

${ }^{45}$ George Makdisi, The Rise of Colleges, h. 128.

${ }^{46}$ Hasan Asari, Nukilan Pemikiran Islam Klasik, h. 96-97.

${ }^{47}$ Zuhairini,dkk, Sejarah Pendidikan Islam, cet. 4 (Jakarta: Bumi Aksara, 1995), h. 99.

Halaqah dan Munazharah...............................................................Asmar
} 
6. Satu-satunya tujuan haruslah mencari kebenaran, siapa pun yang menemukannya;

7. Munazarah tidak boleh terikat oleh aturan-aturan dialektika, seperti larangan seseorang mencabut satu argument atau ilustrasi untuk menggantinya dengan argument atau ilustrasi lain, dan

8. Seseorang mesti memilih lawan ber-munazarah yang diharapkan bisa memberikan pengetahuan, bukan orang yang bisa dikalahkan. ${ }^{48}$

Al-Farabi seperti dikutip oleh Hasan Asari, dengan rinci mengemukakan metode munazarah ini sebagai berikut:

1. A meminta B mengemukakan tesisnya sehubungan dengan topic munazarah: A meminta dengan pertanyaan;

2. A meminta B mengemukakan presmis-premis pendukung tesisnya;

3. A harus meminta premis-premis dari B secara terpisah-pisah, tidak menuntut hubungan-hubungannya;

4. A harus menyatakan bahwa dia telah mendengar cukup premis dan bahwa di (A) telah siap menolak tesis B, lalu A mengajukan sillogismenya;

5. Bila A berhasil mengemukakan sillogisme yang baik maka dia telah berhasil membangun tesis tandingan ('inad);

6. B tidak boleh mengobah/mengingkari premisnya (sebagian atau seluruhnya), kecuali A menafsirkannya secara menyimpang;

7. Pada awal munazarah, B hanya mengemukakan tesisnya. Hanya bila A telah mengemukakan sanggahan, barulah B berhak membela tesissnya. ${ }^{49}$

Sebagaimana ditulis oleh Makdisi bahwa metode debat ini pada mulanya berkembang di Bagdad. Dari kota inilah kemudian menyebar bukan saja ke Spanyol bahkan ke Timur Islam. Tercatat bahwa Abu Abdullah at-Taqafi adalah orang pertama yang membaca ilmu debat dari Bagdad ke Naisabur dan tidak ada yang dikenal memperkenalkan ilmu ini sebelumnya. ${ }^{50}$

Riyasah adalah ajang debat ilmiah untuk mencari orang terbaik di bidangnya telah ditampilkan dalam sejarah Islam. Orang yang terbaik dibidangnya itu kemudian disebut dengan ra'is. Dalam karis akademis, riyasah biasa didapatkan melalui munazarah. Al-Gazali karir akademisnya melejit hinggan "guru besar" setelah gurunya Imam al-Haramain al-Juwaini meninggal.Ia sering terlibat dalam kegiatan munazarah dan mengungguli kontestannya. ${ }^{51}$ Tradisi debat ilmiah untuk mencapai riyasah telah terjadi di Bagdad. Seorang calon ra' is akan menghadapi semua penantang dalam kontes debat. Mereka konsisten untuk mau memenangkan debat. Pemenang debat calon pemimpin akan dipilih orang untuk jadi pemimpin. ${ }^{52}$

\footnotetext{
${ }^{48}$ Hasan Asari, Nukilan Pemikiran Islam Klasik, h. 97-98.

${ }^{49}$ Hasan Asari, Menguak Sejarah Mencari 'Ibrah, h. 189-190.

${ }^{50}$ George Makdisi, The Rise of Colleges, h. 131.

${ }^{51}$ Ibid., h. 186-187.

${ }^{52}$ Ibid., 131.
} 
Tradisi debat seperti di Bagdad ini juga kita temukan pasca reformasi di Indonesia. Debat capres sudah dua periode dilakukan. Pada 2014 ini, kemungkinan besar stasiun TV pun akan melaksanakannya kembali. Sekarang ini, program TV yang menyajikan debat kandidit sangat marak. Namun itu semua, orientasinya ingin kemenangan bukan kebenaran. Selain itu hal yang berbeda dengan sejarah debat di Bagdad, walaupun calon kandidat menang dalam kontes itu, tetapi public belum tentu memilihnya yang bisa jadi di antaranya karena faktor doktrin politik.

Dalam sejarah Islam, tradisi debat dalam berbagai ilmu pengetahuan membuat public tahu para pakar di bidangnya. Tercatat bahwa Sufyan Sauri adalah seorang pakar hadis, Abu Hanifah pakar qiyas, Kisa'i ahli Quran, dan lain-lain. Az-Zahabi membuat daftar para pakar di bidangnya pada abad ke-11. Abu Ishak al-Isfaraini seorang ahli Asy'ariyah. Abdul Jabbar seorang ahli Mu'tazilah. Syeikh al-Muktadir ahli Rafidah. Mahmud bin Sabuktakin ahli fiqh Maliki, dan seterusnya. ${ }^{53}$

Berikut sebagian daftar ra'is di bidang dan daerah masing-masing:

Abu Bistam (w.160/777), ra'is bahasa dan puisi Aran di Basrah. Pada abad ke 4/10 yang menjadi ra'isnya as-Sirafi. Husayn bi. 'Ali al-Basri (w.369/979) adalah ra'is Mu'tazilah, sedangkan an-Nu'man (w. 369/979) adalah ra'is Syi'ah untuk daerah Mesir. Fuqaha Malikiyah menganggap al-Qairawani (w.389/999) sebagai ra'is untuk maghrib dan as-Shibily (w.401/1011) untuk Andalusi. Salah seorang yang pernah menjadi ra'is mazhab Hanafi adalah al-Hasan al-Lu'lu'I (w.204/819). Masing-masing Ibn al-Kajj (w. 405/1014), Syaraf al-Din al-Mausili (w. 589/1193), dan al-Muqaddasi (w. 689/1290) pernah menjadi ra'is al-mazhab as-Syafi' $i$. Pada awal abad ke 5/11, para ra'is untuk berbagai kelompok adalah: al-Isfaraini (A'syariyah), Qadi 'Abd al-Jabbar (Mu'tazilah), Syeikh al-Muqtadir (Rafidiyah), Muhammad b. Haidam (Karramiyah), al-Hammami (Qira'ah), Ibn Sa'id (hadis), al-Sulami (tasauf), Ibn Daraj (linguistic), Ibn Jani (nahwu), Ibn Nabatah (retorika), dan Ibn Habib an-Naisaburi. ${ }^{54}$

Dari perspektif yang positif, tradisi meranking para pakar layak dilakukan, sehingga ketika seorang ilmuan mengutip pendapat para ahli dapat mengetahui posisi atau kualitas pendapat itu. Di UIN Sumatera Utara, Guru Besar Pendidikan Islam, secara informal pun boleh jadi telah diranking sebagian mahasiswa. Tetapi jika ranking itu melalui proses kontes debat, maka itu jauh lebih bertanggung jawab. Kesiapan mental untuk diranking bisa saja belum tumbuh baik pada diri kita, sehingga kita tidak siap dinilai. Sebenarnya pe-ranking-an dalam sistem pendidikan di sekolah maupun Perguruan Tinggi sangat positif jika dilakukan secara jujur. Pembagian fakultas dan jurusan di perguruan tinggi juga secara eksplisit pengakuan terhadap spesialisasi. Dengan sendirinya, ketika memperdebatkan masalah-masalah hukum Islam, Doktor di bidang Pendidikan Islam layak menghormati keunggulan Doktor di bidang Syariah.

\section{PENUTUP}

Halāqah, munāzarah, dan hapalan sebagai metode pendidikan masih dipakai sampai sekarang walaupun tidak seunik di zaman klasik. Halaqah masih berjalan di Mesjid-Mesjid, khususnya di kota-kota besar di Indonesia dengan wajah Majlis Ta'lim atau pengajian, hanya saja tidak lah mengikuti sebagaimana layaknya halaqah dalam sejarah Islam dari sisi metode. Munazarah pun banyak digunakan, tetapi tidaklah untuk

\footnotetext{
${ }^{53}$ Ibid.,h. 132.

${ }^{54}$ Hasan Asari, Menguak Sejarah Mencari 'Ibrah, h. 186. Halaqah dan Munazharah.
} 
mencari ra'is-ra'is dalam berbagai bidang keilmuan. Di Indonesia yang sering munazarah "caleg dan capres". Kalau sekedar berdebat, berdiskusi di kampus-kampus umumnya menggunakan ini. Metode menghapal sangat jelas masih tetap hidup dan relevan untuk bidang tertentu, khususnya hapalan Alquran. Ada bidang studi tertentu memang tidak boleh berhenti pada hapalan, tetapi harus dilanjutkan menuju pemahaman. Semua bidang studi ada yang harus dihapalkan.

Studi Islam yang dikembangkan di kampus-kampus atau di "halaqah-halaqah ekslusif" barangkali bisa menghidupkan kembali tradisi metode halaqah dengan mengedepankan rasionalitas dan kritisisme, di mana sikap keterbukaan untuk berbeda dikembangkan walaupun dengan guru sendiri dengan orientasi untuk mencari kebenaran. Munazarah sebagaimana disebut Hasan Asari sesuatu yang hilang dalam pendidikan Islam, perlu kita temukan lagi dan di dunia akademis sangat kita butuhkan untuk mengetahui ra'is-nya. Metode menghapal perlu dikembangkan bukan saja untuk menghapal Alquran, tetapi menghapal hadis. Barangkali fard kifayah lah bagi kita ada yang menghapal hadis saja walaupun ia tidak paham, karena menghapal 100.000 hadis untuk menjadi seorang hafiz hadis membutuhkan konsentrasi yang ekstra. Pada bidangbidang lainnya menghapal digunakan untuk seperlunya berdasarkan orientasi keilmuannya.

\section{DAFTAR PUSTAKA}

Abduh, Muhammad. Tafsir Juz 'Amma. terj. Haidar Bagir. cet. 5. Bandung: Mizan, 1999.

Al-Gazali, Ihya Ulum ad-Din. Semarang: Toha Putra, t.t. Jilid I.

Al-Qattan, Manna Khalil.Mabahis fi 'Ulum al-Qur'an.Riyad: Mansyurah al-'Asar alHadis, 1973.

Al-Yassu'i, Fr. Louis dan Fr. Bernad Tottel al-Yassu'i, Munjid, cet. 28 (Beirut: Dar ElMachreq Sarl Publisher, 1986.

al-Zarnuji. Ta'lim al-Muta'allim Tariqatu at-Ta'lim. Mesir: Dar al-Kutb al-Misriyah, t.t..

Asari, Hasan. Menguak Sejarah Mencari 'Ibrah. Bandung: Cita Pustaka, 2006.

Asari, Hasan. Menyingkap Zaman Keemasan Islam: Kajian atas Lembaga-Lembaga Pendidikan. Bandung: Mizan, 1994.

Asari, Hasan. Nukilan Pemikiran Islam Klasik.Yogyakarta: Tiara Wacana Yogya, 1999

As-Saleh, Subh.Membahas Ilmu-Ilmu Hadis.terj. Tim Pustaka Firdaus. cet. 5. Jakarta: Pustaka Firdaus, 2002.

As-Syarifi, Syauqi as-Sayyid.Mu'jam Mustalahat al-'Ulum al-Tarbawiyah. Riyad: Maktab al-Abikan, 2000. 
At-Tanahi, Thahir.Durusun min al-Qur'an li al-Ustad al-Imam al-Syeikh Muhammad Abduh.Cairo: Dar al-Hilal, t.t.

Azra, Azyumardi. Jaringan Ulama TImur Tengah dan Kepulauan Nusantara Abad XVII\&XVIII: Edisi Perenial. Jakarta: Kencana, 2013.

Jumantoro, Totok. Kamus Ilmu Hadis. Jakarta: Bumi Aksara, 1995.

Makdisi, George. The Rise of Colleges. Edinburgh: Edinburg University Press, 1981.

Mushaf Firdaus. Jakarta: Pustaka Firdaus, 2013.

Rahman, Fazlul. Islam dan Modernitas.terj. Ahsin Mohammad. cet. 2. Bandung: Pustaka, 1995.

Republika.co.id 12 Februari 2014.

Saleh, Akh. Muwafik.Membangun Karakter dengan Hati Nurani. Jakarta: Erlangga, 2012.

Stanton, Charles Michael. Pendidikan Tinggi Dalam Islam: Sejarah dan Peranannya Dalam Kemajuan Ilmu Pengetahuan. terj. Afandi dan Hasan Asari. Jakarta: Logos, 1994.

Syalabi, Ahmad. Sejarah Pendidikan Islam.terj. Muchtar Jahya dan M. Sanusi Latief. Jakarta: Bulan Bintang, 1973.

Syalabi, Ahmad. Tarikh at-Tarbiyah al-Islamiyah.Beirut: Dar al-Kasysyaf, 1945.

Zuhairini,dkk. Sejarah Pendidikan Islam.cet. 4. Jakarta: Bumi Aksara, 1995. 